doi.org/ 10.51891/rease.v8i2.4239

\title{
O IMPACTO NEGATIVO NA APRENDIZAGEM FRENTE AO DESCASO ESCOLAR
}

\author{
Sabrinna Ingrid Montenegro Castelo ${ }^{1}$ \\ Erika Regine de Melo Montenegro ${ }^{2}$
}

RESUMO: $O$ interesse pelo tema surgiu através da vivência em estágio supervisionado e através da experiência em sala de aula de uma das autoras do artigo, onde foi observado que o descaso familiar pode gerar consequências na aprendizagem. A família tem a importância desde o início do desenvolvimento cognitivo e motor do indivíduo, até os primeiros anos de estudo no âmbito escolar, se essa participação familiar for negada à criança, isso poderá impactar negativamente na aprendizagem. Partindo desse ponto, começamos uma leitura sobre a importância da família no processo da aprendizagem, buscando investigar o impacto negativo na aprendizagem frente ao descaso familiar. $\mathrm{O}$ aprendizado inicial que começa dentro do ambiente familiar está interligado ao desenvolvimento motor e cognitivo da criança. A leitura científica foi fundamentada nas concepções de Simaia Sampaio (20II), Visca (1991), Sena e Gomes (2004). A pesquisa iniciou com um breve histórico sobre a aprendizagem no âmbito familiar, apresentando seus os estágios, a importância da participação da família e qual o impacto negativo do descaso familiar. Será apresentado nesse artigo também, todo o trabalho desenvolvido no Estágio Supervisionado. A partir dos estudos realizados, foi possível perceber que a participação da família está intimamente ligada à base da aprendizagem.

Palavras-Chave: Descaso familiar. Aprendizagem. Família.

ABSTRACT: The interest in the subject arose through the experience in a supervised internship and through the classroom experience of one of the authors of the article, where it was observed that family neglect can have consequences in learning. The family is important from the beginning of the individual's cognitive and motor development, until the first years of study in the school environment, if this family participation is denied to the child, this can negatively impact learning. From this point, we began a reading about the importance of the family in the learning process, seeking to investigate the negative impact on learning in the face of family neglect. The initial learning that begins within the family environment is linked to the child's motor and cognitive development. The scientific reading was based on the concepts of Simaia Sampaio (20II), Visca (1991), Sena and Gomes (2004). The research began with a brief history of learning within the family, presenting its stages, the importance of family participation and the negative impact of family neglect. It will also be presented in this article, all the work developed in the Supervised Internship. From the studies carried out, it was possible to perceive that family participation is closely linked to the basis of learning.

Keywords: Family neglect. Learning. Family.

\footnotetext{
'Especialista em Psicopedagogia Institucional, Clínica e Organizacional pelo Instituto Dom José de Educação e Cultura (IDJ). Graduada em Ciências Contábeis pela Faculdade Integrada do Ceará - FIC e em Marketing Estratégico pela Universidade Paulista - UNIP.E-mail: sabrinnaingrid@icloud.com.

2 Especialista em Psicopedagogia Institucional, Clínica e Organizacional pelo Instituto Dom José de Educação e Cultura (IDJ) e em Gestão e Coordenação Escolar pela Faculdade de Tecnologia Darcy Ribeiro. Graduada em Pedagogia - Licenciatura pela Universidade Estadual Vale do Acaraú (UVA). Docente na rede pública de ensino de Fortaleza. E-mail: montenegroe6ı613@gmail.com. ORCID: *oooo-ooo3-4549-6997.
} 


\section{INTRODUÇÃO}

Devido aos diversos estudos sobre as dificuldades no processo de aprendizagem, os fatores orgânicos deixaram de ser o único motivo que causam problemas neste contexto. Tais fatores podem, de fato, prejudicar a aprendizagem, mas investigar outras causas é um caminho para entender que o aluno não é o único responsável por seu fracasso escolar.

O interesse por essa pesquisa surgiu diante da experiência das autoras a partir do estágio supervisionado com uma estudante do $3^{\circ}$ ano do Ensino Fundamental I de uma escola pública de Fortaleza, Ceará. Durante o estágio, foi possível perceber que a criança apresentava desinteresse e falta de concentração nos conteúdos, pois o que estava sendo ensinado parecia difícil e não porque a criança possuísse algo déficit de atenção. Alguns casos de crianças que não assimilam os conteúdos podem revelar consequências do descaso familiar.

"Ninguém pode aprender acima do nível da estrutura cognitiva que possui" (VISCA, 1991, p. 52). Optamos em pesquisar a importância da participação familiar no desenvolvimento cognitivo, pois a realidade vivida em nosso estágio e a situação em muitas escolas públicas é complicada, a quantidade de crianças com desenvolvimento atrasado e que apresentam desinteresse e dispersão é grande, sendo que isso muitas vezes é apenas no ambiente escolar. Mediante a docência de uma das autoras e experiência adquirida das duas autoras no estágio supervisionado, surgiram alguns questionamentos: Por que existem alunos de escolas públicas que apresentam em seu comportamento atitudes dispersas em sala de aula resultando na dificuldade em assimilar o conteúdo? Será que a causa dessa desatenção está relacionada às primeiras aprendizagens que acontecem no ambiente familiar? De acordo com Visca (I99I, p. 68, apud Sampaio, 20II, p. 7I) as primeiras aprendizagens são realizadas na família, estendendo-se, posteriormente, ao bairro e à escola.

Nossa investigação teve o objetivo de descobrir quais impactos negativos do descaso familiar refletem na aprendizagem, pois essa realidade está presente na criança com a qual fizemos o estágio. O problema que existe na mesma gera dificuldade na compreensão do conteúdo ensinado. Após a conclusão dessa investigação, iniciaremos a 
intervenção para promover um desenvolvimento cognitivo e assim melhorar o aprendizado.

Observamos que a criança do estágio apresenta defasagem cognitiva, tem in anos e após as provas operatórias, concluímos que possui idade cognitiva de 6 anos, isso é explicado por Sampaio (20II), ao afirmar que: "Quando uma criança de nove anos está em um nível pré-operatório, mas já deveria estar no operatório concreto, existe o que chamamos de defasagem cognitiva" (SAMPAIO, 20II, p. IO7).

A pesquisa sobre a participação familiar na aprendizagem, foi um dos caminhos que optamos para investigar as causas dessa defasagem, pois a realidade familiar da mesma é marcada por descaso por parte dos pais em relação aos estudos da mesma. Buscar informações desde a gravidez da mãe, que foi de primordial importância pois a ausência de estímulos e de um acompanhamento familiar podem atrasar o desenvolvimento infantil.

A metodologia utilizada para desenvolver a pesquisa foi qualitativa e quantitativa, sendo uma pesquisa tipo estudo de caso. Os principais autores que fundamentam a pesquisa são: Simaia Sampaio (2011), Sena e Gomes (2004) Buriolla (200I), Ferreira (200I), Weiss (2004) e Visca (199I). A estrutura desse artigo está dividida nas seguintes partes: Aprendizagem no âmbito familiar, Os estágios da aprendizagem, A importância da participação da família, Impacto negativo do descaso familiar e Estágio Supervisionado: Análise de dados.

\section{APRENDIZAGENS NO ÂMBITO FAMILIAR}

As primeiras aprendizagens de um indivíduo acontecem no ambiente familiar, logo nos primeiros meses de vida e assim começa a ser construído o desenvolvimento cognitivo e motor da criança, segundo SAMPAIO (200I, p. 74) “Antes de entrar na escola, a criança deveria receber seus primeiros estímulos em casa".

Aprender a mamar, rolar no berço, segurar a mamadeira, levantar a cabeça, comer de colher, sentar, engatinhar, falar, andar e dançar são habilidades adquiridas através do estímulo e ensino no ambiente familiar.

No momento em que a criança conquista cada conhecimento citado no parágrafo anterior, percebe-se a grande importância da família em estimular, pois são eles os primeiros que presenciam e são atitudes participativas como essas que farão a criança adquirir novas habilidades no tempo certo de seu desenvolvimento. 
Quando observada a interação dos membros familiares, sabe-se como o conhecimento é repassado e qual acesso existe à aprendizagem nesse ambiente. Cada membro tem seu modo de assimilar e passar qualquer conhecimento e comportamento (MUNHOZ, 2005, p. 180 apud SAMPAIO, 2011).

Logo no início do desenvolvimento desse tópico, foi possível perceber a importância da família no processo de aprendizagem, pois o ato de aprender começa nas experiências do indivíduo com a interação familiar. Observar a importância que a aprendizagem tem para os membros da família é um caminho para entender quem ensina e quem aprende, sendo isto primordial para a produção do conhecimento.

O estímulo do pensamento é indispensável na base do aprendizado, que começa desde de cedo fazer a criança pensar nas suas atitudes e responder pelas consequências das suas escolhas, deixá-la ela ter autonomia, desenvolver o ato de ouvir seus questionamentos e dar limite à mesma.

As atitudes opressoras ou até mesmo as famílias que não dão a liberdade adequada às crianças, muitas vezes podando-as em quase tudo, seja no falar, pensar e até mesmo repreendendo a forma de agir da criança, trazem consequências impactantes na formação do ser. Algumas crianças apresentam dificuldades em interpretar, elaborar uma redação e até mesmo tomar decisões perante os amigos, devido a um comportamento submisso e inseguro, consequência de algumas famílias que restringiram as crianças, impedindo-as de pensar, fazer suas próprias escolhas ou até mesmo serem ouvidas, pois o ambiente familiar está carregado de estresse, segundo SAMPAIO (20II, p. 78): "Falta de paciência, ameaças constantes, podendo gerar problemas emocionais, tais com baixa autoestima, depressão, angústia, fobias”.

Algumas respostas do mau desempenho escolar estão no meio familiar. Muitas vezes as famílias estão convictas de que suas atitudes são corretas e que elas não impactaram negativamente no processo de aprender da criança, mas é no núcleo familiar que são formados muitos indivíduos frustrados e com autoestima baixa.

Não observar a importância do apoio e participação familiar nos primeiros anos de vida de uma criança podem ser o início de de problemas futuros na escola, podendo ocasionar fracasso escolar.

A falta de compreensão, atitudes egoístas por parte de quem deveria educar e não ter a sensibilidade em relação às emoções da criança, que é um ser com sentimentos e 
vontades como qualquer adulto, podem prejudicar a autoconfiança e estagnar o seu desenvolvimento. Autoconfiança é a convicção que uma pessoa tem de ser capaz de fazer ou realizar alguma coisa, se desde cedo a criança não tem atenção e não é estimulada a desenvolver suas competências, isso pode gerar um sentimento de incapacidade e bloquear o aprendizado. Percebe-se nessa pesquisa que as aprendizagens familiares são as que geraram frutos futuros e que ela é a base da formação do conhecimento alicerçado.

\section{OS ESTÁGIOS DA APRENDIZAGEM}

Nos primeiros dias de vida, já inicia-se a aprendizagem de um ser humano e esse conhecimento não é estimulado como deveria em algumas crianças. Muitas famílias acreditam que a construção do aprendizado só começa no momento em que a mesma tem contato com a escola, que as conquistas anteriores do indivíduo só se deram por causa do curso natural do desenvolvimento infantil, devido a isso, muitas crianças já iniciam seus estudos com atraso, pois a família não estimulou além do que a criança estava desenvolvendo naturalmente.

As primeiras aprendizagens não são no ambiente escolar, elas iniciam bem antes e para entender melhor Visca (199I, p. 68, apud SAMPAIO. 20II, p. 7I) dividiu a aprendizagem em 4 estágios, são eles: I) Protoaprendizagem, 2) Deutoraprendizagem, 3) Aprendizagem assistemática e 4) Aprendizagem sistemática. É possível perceber a importância do aprendizado em cada estágio e que eles estão interligados, se existir uma lacuna entre eles, quando a criança iniciar os estudos, a dificuldade aparecerá.

O primeiro estágio que se chama Protoaprendizagem, tem um papel fundamental para o desenvolvimento dos demais estágios e consequentemente a formação básica de uma eficaz aprendizagem. Segundo Sampaio (20II, p. 7I) "protoaprendizagem é o resultado da interação da criança com a mãe, sendo portanto, o estágio das primeiras relações vinculares".

Estudando sobre cada estágio, é possível perceber a importância do primeiro, pois consiste na interação da criança com a mãe, momento de troca, doação, cumplicidade e amor. Valorizar esse tempo e saber aproveitar as oportunidades que são dadas são de grande valia, pois começa um caminho positivo da eficaz aprendizagem.

Perceber a criança como um indivíduo que capta tudo ao seu redor, mas da sua maneira, é primordial para que aconteça um desenvolvimento cognitivo e motor, que são 
as bases da aprendizagem. Se esse momento for bastante estimulado, tanto pela mãe como por toda a família, o próximo estágio, que recebe o nome de Deutoraprendizagem, será atingido e o indivíduo avançará e precocemente terá uma visão dos objetos animados e inanimados, isso é explicado, segundo Sampaio (2011, p. 7I): "Deutoraprendizagem consiste no contato do sujeito que alcançou a protoaprendizagem com o grupo familiar que lhe possibilitou adquirir uma precoce visão dos objetos animados e inanimados”.

Nos dois primeiros estágios, são períodos onde o desenvolvimento motor inicia. $\mathrm{O}$ cérebro tem a capacidade de comandar os movimentos do corpo, nesse estágio é importante focar na coordenação motora, a criança começa seus equilíbrios estimulados pelo cérebro nesse tempo.

Durante toda a nossa vida, a coordenação motora tem sua importância, principalmente nos domínios psicomotores e cognitivos. A insegurança é um aspecto que tem que ser analisado desde cedo, desenvolver a autoconfiança de um indivíduo nos primeiros anos de vida dele. Quando o organismo começa a processar informações e provocar estímulos, isso afeta diretamente na segurança e no domínio do agir de um ser. $\mathrm{O}$ domínio postural adquirido, o cérebro aprende a motricidade e a atividade simbólica ficam estimulados.

Há evidências que algumas dificuldades de movimentos em algumas crianças são desordens acompanhadas por dificuldades emocionais e sociais e esses problemas também são comportamentais, acompanhados de baixa autoestima, não aceitam as responsabilidades, possuem dificuldades em traçar metas e baixa competência social. Se observamos cada detalhe apresentado, percebemos que a motivação é o ponto básico para a confiança em si mesmo. A motivação começa dentro da família e estimular uma criança através dos diversos aprendizados, que a princípio são motores e cognitivos, ajudarão na formação da complexa aprendizagem.

Quando iniciam os estudos escolares, percebe-se a importância da coordenação motora e muitas escolas elaboram atividades que trabalham essa coordenação, pois através disso acreditam que os alunos percam a ansiedade e a insegurança e adquiram equilíbrio, força, resistência e obtenham um melhor rendimento, então é reforçado a partir dessas informações a importância primordial da aprendizagem nos primeiros anos de vida, que são de responsabilidade familiar. Se esses estágios forem levados a sérios, provavelmente muitos casos de dificuldade na aprendizagem nunca teriam surgidos. 
Passando por cada estágio anterior de forma positiva, a criança conquistará novas habilidades ao entrar no terceiro estágio, que é a aprendizagem assistemática. Esse período é importantíssimo na base da formação do conhecimento da criança, é o momento onde ela terá contato com o social, seja nos parquinhos, encontros com outras crianças e assim ela assimilará um novo aprendizado que ainda não é o institucional, segundo Sampaio (201I, p. 7I): “Aprendizagem assistemática, elaborada por meio do vínculo entre o sujeito e a comunidade restringida, o que permite adquirir conhecimento que ainda não são os da instituição educativa".

"Aprendizagem sistemática resulta da interação do sujeito com a instituição" Sampaio (20II, p. 7I), só será desenvolvida de forma natural se a família tiver observado a importância do aprendizado desde cedo, pois a mesma tem total responsabilidade para que o quarto estágio, que é aprendizagem sistemática, seja bastante produtivo, pois a formação do conhecimento, que antecede a entrada da criança na escola, só depende da interação que os membros da família permitiram à criança.

Privá-la de um contato social atrasa o desenvolvimento da mesma, por isso muitas crianças apresentam dificuldade ao ingressar nos estudos, por conta da falta de interesse por parte dos familiares de envolver essa criança na comunidade em que vivem. É muito normal vermos nos dias atuais os parquinhos e as praças desocupadas e as crianças e até mesmo os bebês dentro de casa sendo expostos exageradamente a celulares, tablets e televisões. Atitudes assim impactam totalmente na futura vida estudantil da criança.

\section{A IMPORTÂNCIA DA PARTICIPAÇÃO DA FAMÍLIA}

A família tem importância primordial e contínua na construção do conhecimento, pois as primeiras aprendizagens iniciam no âmbito familiar e continuam no ingresso na escola. Muitas famílias acreditam que a criança só começa realmente aprender quando está estudando e que a família já não precisa participar dessa construção do aprendizado, mas segundo Sena, (2004, p. 88): “A possibilidade de ser alfabetizado não ficava reduzida à instituição escolar. Os próprios pais inventavam diversas alternativas para oferecer aos filhos um pouco de instrução".

A coordenação motora é desenvolvida logo cedo, sendo primordial para o aprendizado, ela consiste na capacidade do cérebro de equilibrar os movimentos do corpo. Quando a criança começa a rastejar, andar, correr, pular, subir e descer escadas, já é 
percebida a capacidade infantil para desempenhar essas funções devido à coordenação motora. É muito importante o estímulo familiar nessa etapa infantil, pois é neste âmbito que a mesma inicia o desenvolvimento desta capacidade, então é necessário a família estar presente em cada etapa.

A coordenação motora capacita também, através dos músculos, a ação de pintar, desenhar, encaixar, montar, abotoar e até mesmo escrever. Todas essas ações acontecem, em sua grande maioria, antes do ingresso na escola, sendo ensinadas pela família ou até mesmo por grupos sociais. A participação familiar em cada aprendizado terá resultados positivos mais à frente e assim a família se torna a base mais importante para a formação motora do indivíduo.

A cognição é um processo de aquisição do conhecimento e está relacionada ao pensamento, memória, raciocínio e percepção e através de todos esses tópicos acontece o desenvolvimento intelectual.

Os padrões de comportamento são um resultado da própria cognição e esses nem sempre são os desejáveis, por isso que a construção do intelecto começa desde cedo, dentro dos padrões da família na qual essa criança está inserida. "Observamos, pois, que a base se dá na família. É por meio dela que o sujeito se estrutura, cria vínculos afetivos, inicia seu desenvolvimento cognitivo emocional” (SAMPAIO, 2oII, p. 76). A contribuição familiar no desenvolvimento cognitivo é primordial, pois essa área compreende a maneira como as pessoas aprendem, percebem, recordam e todos os padrões ensinados pela família impactam no comportamento da criança.

Captar uma realidade em sua totalidade é algo quase impossível para um ser sozinho, a participação da família nessa captação do aprender pela criança facilitará o processo das informações de seu meio e assim ela aprenderá a cumprir tarefas e desempenhar um comportamento em um ambiente social.

O desenvolvimento cognitivo nada mais é que o aprimoramento das habilidades já conquistadas através do desenvolvimento motor, pois o cérebro tem funções que abrigam essas habilidades adquiridas desde de cedo.

A família é a responsável para auxiliar no desenvolvimento físico, emocional e intelectual de uma criança, sua participação eficaz nessa etapa do aprender trará uma motivação e equilíbrio emocional desse ser. 


\section{IMPACTO NEGATIVO DO DESCASO FAMILIAR}

Iniciamos esse tópico com a seguinte linha de raciocínio: algumas crianças já iniciam seus estudos com impacto negativo do descaso familiar, pois a família ignorou a importância das primeiras aprendizagens, que vão desde dos primeiros contatos com os membros da família até o início da interação social. Segundo Gomes (2004, p. 9): “Na tentativa da explicação do fracasso escolar, foram analisados os aspectos sociais, escolares e psicolinguísticos”.

É comum observar crianças com dificuldades ou até mesmo transtornos devido às sequelas emocionais e sociais que surgiram bem antes do ingresso ao ambiente escolar. Isso é observado algumas vezes até mesmo no difícil processo de adaptação escolar. Crianças que tiveram pouco contato social foram privadas do aprendizado que é adquirido com outras crianças nos parquinhos, passeios e que muitas vezes não aconteceram devido a uma superproteção ou até mesmo atitudes erradas em expor precocemente a criança a tablets, celulares ou até mesmo à televisão, com intuito de entreter, se isentando da tarefa tão essencial do ensinar ou melhor, estimular a mesma ao seu desenvolvimento.

Segundo Sampaio (2011, p. 75): “O que presenciamos hoje são crianças que já

acordam ligadas à televisão ou mesmo ao computador e não falamos somente de crianças maiores, mas também de crianças de apenas dois anos de idade, cujos pais, por comodismo ou por ausência, se esquecem de oferecer outros recursos”.

A família erra quando isenta a criança do convívio social e isso também pode ser caracterizado como descaso familiar. Cada idade tem sua etapa de desenvolvimento e todas as partes da construção do mesmo devem maduras e íntegras de acordo com a idade, pois assim haverá conexão de maneira eficaz e ocorrerá uma resposta positiva do cérebro aos estímulos do ambiente. Tudo isso resultará na concretização da aprendizagem e evolução adaptativa para novos conhecimentos.

Quando a família não participa de forma eficaz do desenvolvimento cognitivo infantil, poderá ocorrer um impacto negativo na construção da autonomia do indivíduo. Se o desenvolvimento não for trabalhado, pode passar despercebido algum sinal que denote um possível atraso. Segundo Sampaio (20II, p. 76) "Não é na escola que o desenvolvimento começa, como pensam erroneamente muitos pais, grande parte de alguns problemas e 
conflitos entre a escola e a família reside aí, quando alguns pais querem atribuir o dever de ensinar e educar apenas à escola, sem participar da educação".

Famílias que não estimulam a coordenação motora de forma frequente, perdem a oportunidade de analisar a criança, se a mesma está respondendo aos estímulos e assim, não terão meios de detectar alguma deficiência que poderia ser tratada através de práticas que estimulem a melhoria, como é o caso das atividades físicas que fazem com que a criança estimule o cérebro e o corpo. $O$ descaso familiar em relação à importância do seu papel no desenvolvimento da coordenação motora poderá tornar a criança um ser inseguro, pois o primeiro passo, que seria capacitá-la por meio de uma adequação própria, não será ampliado e estimulado para assim processar as informações e ações.

Os domínios psicomotores e cognitivos são resultados da coordenação motora, que é importante ao longo da vida de cada pessoa. A ausência familiar nesses desenvolvimentos básicos pode fazer com que a criança não adquira um domínio postural e o cérebro não aprenda a motricidade, afetando a percepção simbólica. Algumas dificuldades desses movimentos foram geradas por desordens acompanhadas por problemas emocionais e sociais, que vão desde problemas comportamentais, baixa autoestima, estabelecimento pobre de metas, autoconceito muito baixo, fraca inclinação para aceitar responsabilidades e competências sociais escassas.

Quando as crianças ingressam no ambiente escolar, é percebida a importância da coordenação motora para as atividades escolares, logo, as escolas colaboram com tais atividades de coordenação motora para que os alunos percam a ansiedade, insegurança e adquiram equilíbrio, força e resistência, melhorando assim seu rendimento. Se a criança ingressar nos estudos com defasagem nesse aspecto, ela apresentará muitas características negativas que impactarão em seu processo de aprendizagem.

\section{ESTÁGIO SUPERVISIONADO}

O estágio supervisionado foi o ponto de partida para essa pesquisa, pois a investigação sobre a importância da família no processo de aprendizagem foi de fundamental importância para entender os motivos que levaram essa criança analisada a apresentar um atraso cognitivo tão severo.

De acordo com Visga (1991, p. 52): “Ninguém pode aprender acima do nível da estrutura cognitiva que possui”. O fato da criança ter a idade cronológica de il anos e a 
cognitiva de 6 anos foi uma descoberta que serviu de norte para entendermos a origem das dificuldades de aprendizado da aluna. O local do estágio foi um espaço psicopedagógico situado em Fortaleza, Ceará.

Os pais apresentaram a queixa e a escola pontuou o atraso escolar da aluna T.G.R.G. de II anos, que cursava o Ensino Fundamental. Foi feita a anamnese nessa etapa e foi observado que, ainda nos primeiros meses de vida, ela já sofria com o descaso familiar.

A aplicação das provas operatórias tem como objetivo determinar o nível do pensamento do sujeito, realizando uma análise quantitativa e reconhecendo as diferenças funcionais realizando um estudo predominantemente qualitativo (VISCA,1995, p. II). As provas operatórias são de muita valia para a análise do diagnóstico. Aplicando as mesmas nos atendimentos, é possível detectar o nível cognitivo da criança e assim fazer uma análise quantitativa e qualitativa da situação de forma eficaz.

\section{ENTREVISTA OPERATIVA CENTRADA NA APRENDIZAGEM (EOCA)}

A realização da EOCA tem como objetivo investigar o modelo de aprendizagem do aluno e seu vínculo com os objetos e com os conteúdos escolares. A criança não sabia o motivo de estar lá, ela respondeu que ali era um reforço escolar. Nessa hora, explicamos o motivo da sessão, falamos também da importância de aprender e que muitas coisas que ela aprende na escola aparecerão no dia a dia.

Deixamos um estojo escolar com vários itens e percebemos que ela se dispersa facilmente com os objetos, pegou uma bexiga que tinha dentro e assim percebemos que mesmo em um momento voltado para a aprendizagem, ela não se interessa por itens voltados ao estudo e apresenta dificuldade na leitura e com a Matemática, então usamos um livro do Io ano para detectar em qual nível cognitivo ela se encontrava.

Observamos como ela pega no lápis, como pinta, se reconhece as cores. Descobrimos que o motivo dela não fazer contas de divisão e nem de multiplicação é porque não sabe somar nem subtrair. Não domina os conceitos matemáticos sobre unidade, dezena e centena e não sabe quando um número é par ou ímpar. Algumas vezes trocou nome das cores e tem dificuldades de observar espaços. A aluna começou uma pintura e parou antes de concluir, acreditando que está bom. Não sabe discernir o lado direito e do esquerdo e nem conhece os números de o a 9 na sequência. Concluímos, 
portanto, que a mobilidade de aprendizagem da mesma é HIPERASSIMILIDADE E HIPOACUMULATIVA.

\section{TESTE DE PSICOGÊNESE DA ESCRITA}

O Nível de escrita da aluna é o silábico alfabético, a criança é leitora de palavras simples, possui nível de escrita e leitura de uma criança de 6 anos do I $^{\mathrm{o}}$ ano do Ensino Fundamental I. Observamos a temática, a dinâmica e o produto.

\section{PROVAS OPERATÓRIAS}

- Seriação: Não conseguiu colocar em ordem crescente e nem decrescente;

- Prova dos pequenos conjuntos discretos de elementos:_Não tem noção de espaço, quando afasta as fichas, a aluna acha que tem mais e quando aproxima, ela acha que tem menos;

- Conservação de matéria:_Quando as massas estão no mesmo formato e tamanho ela entende que são iguais, mas quando fizemos o formato de bola em umas das massas, a criança afirmou que uma massa tem menos que a outra;

- Conservação do líquido:_Colocamos o líquido em dois copos iguais e ela afirmou ter a mesma quantidade de água, em copos diferentes afirmou que o mais fino tem menos água e longo tem mais água. Ao retornar para os primeiros copos, a aluna disse que está em quantidade igual.

Descobrimos que a mesma apresenta defasagem cognitiva, pois nenhuma prova aplicada para o nível da idade cronológica dela foi atingida com êxito. Aplicamos provas para nível de 6 a 8 anos e de 9 a II anos e em nenhuma ela correspondeu ao objetivo traçado.

\section{VÍNCULO}

\section{TÉCNICAS PROJETIVAS}

- Vínculo escolar:

Par educativo: Conforme a posição do desenho, a criança tem o perfil exigente regressivo, pois o desenho foi feito na parte superior esquerda. Em relação ao título, ela não associou ao conteúdo, mas sim a uma pessoa do desenho. Apresentou negação à 
aprendizagem, pois o ambiente desenhado não correspondia ao ensino. Outro relato de negação foi não querer colocar seus colegas no desenho, pois relatou que sofria bullying por parte deles. O desenho feito foi pequeno, comprovando que ela realmente sofre bullying como relatou apresentando caraterísticas de submissão, desvalorização e sente-se vítima no grupo.

Foi percebido que a aprendizagem é assistemática, pois escolheu um ambiente extraescolar. A melhor forma de aprendizagem da mesma é através dos contatos primários (família e grupo sociais.). Ela observa muito o comportamento dos mais velhos com quem convive e a melhor forma de aprendizagem é do cotidiano. O desenho mostrou a criança lado a lado com professor, o que significa uma comunicação superficial, relação deficitária com os colegas e grande afetividade pelo docente. Segundo a criança, esse professor dá mais atenção à mesma.

\section{- Vínculo familiar}

Os desenhos dos quatro momentos do dia foram na residência, mostrando um forte vínculo familiar e estilo de vida monótono. O tipo de aprendizagem melhor para ela é a aprendizagem realista e a mesma é tolerante à frustação, por isso que os pais nem perceberam o quanto impacta na mesma as críticas recebidas na sala de aula.

- Vínculo consigo mesma

No desenho do dia do seu aniversário, ela não desenhou convidados, apenas os pais e o ambiente é a casa dela. Se desenhou de costas para os pais, mostrando que possuem vínculo negativo com a aprendizagem e isto está bem claro dentro dela.

No desenho das férias, a criança se viajando com a mãe, com uma mala e em nenhum momento desenhou o que mais gosta nas férias, isso demonstra que seu vínculo com as atividades escolares é distante. No desenho que mais gostou, ela se desenhou coerente com a realidade, mostrando atos falhos, contradição e incoerência.

\section{CONTO}

A criança relatou que os colegas a chamavam de feia e burra na sala de aula. Trabalhamos o conto com a mesma para saber qual impacto de tudo isso em sua autoestima e emoções.

Contamos um conto e falamos das características da personagem. Focamos em ressaltar que a beleza mais destacada da princesa eram as atitudes humanas e a dedicação a 
tudo que ela fazia, não focamos na beleza exterior. Na etapa final dessa sessão colocamos uma música, intitulada Eu Acredito em Contos de Fadas e, ao som da mesma, pedimos para a criança desenhar ela mesma como uma princesa. Ficamos impressionadas quando percebemos que ela desenhou uma bruxa na história.

\section{DIAGNÓSTICO - DEVOLUTIVA DIA 16/12/2019}

A menor T.G.R.G apresenta dificuldade de aprendizagem, a mesma se encontra com idade cognitiva de 6 anos e deveria estar no período operatório concreto, mas se encontra ainda no pré-operatório. Apresenta defasagem cognitiva no processo de assimilação e acomodação de conteúdo, sendo este mais elevado do que sua capacidade de compreensão

Existe um grande impacto emocional na criança, o fato da mesma não ter rotina de estudos, não ter um lugar específico para fazer suas atividades em casa, não ter horário correto para dormir e acordar, nem atenção familiar em seus estudos e brincadeiras tem impactado negativamente no processo de aprendizagem e autoconfiança fatores detectados, através das técnicas desenvolvidas na etapa do diagnóstico e nas conversas com a criança durante todo o período de estágio.

\section{INTERVENÇÃO}

Os pais deverão:

I) levar a filha ao neurologista, com o intuito de descobrir se a defasagem cognitiva é uma consequência de um problema orgânico. Também deverão iniciar um acompanhamento psicológico para trabalhar a autoestima, emoções e autoconfiança, continuar com a professora particular e começar um atendimento psicopedagógico após o laudo do neurologista;

2) Devem também estabelecer uma rotina para melhorar seu rendimento escolar e vínculo familiar, oferecer livros infantis e proporcionar atividades que envolvam socialização, como o vivências com crianças da mesma idade, estimulando seu desenvolvimento;

3) Aplicar metodologias baseadas em Psicodrama e Psicomotricidade para facilitar sua assimilação;

4) Usar recursos didáticos que despertem o interesse e desejo de aprender; 
5) Promover lazer em família;

6) Ir ao oftalmologista, pois a criança relatou que não enxergar o que está na lousa.

\section{RECURSOS UTILIZADOS NA INTERVENÇÃO}

Ilustração oI - Material para aplicação das provas operatórias de seriação e pequenos conjuntos discretos de elementos.

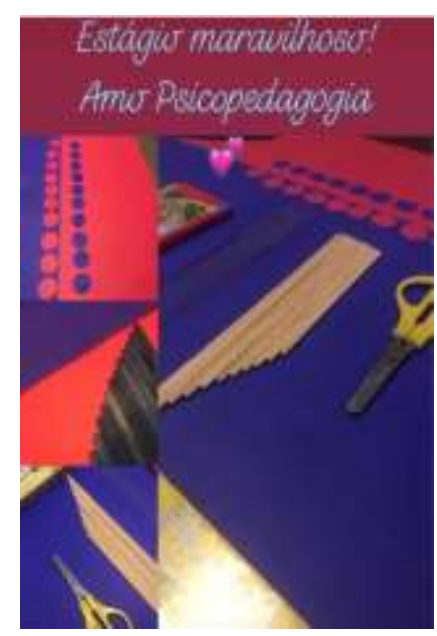

Fonte: Acervo das autoras (2019).

A foto acima mostra o material elaborado para a aplicação das provas operatórias, seriação e pequenos conjuntos discretos de elementos. Foi utilizado: cartolinas dupla face nas cores vermelha e azul, palitos de picolé e palitos para churrasco. Moldamos os palitos em vários tamanhos. Esses materiais foram usados para analisar se a aluna tem noção de espaço e se entende ordem crescente e decrescente.

Ilustração o2 - Ilustração dos jogos dama, dominó, jogo da memória e caça-palavras.

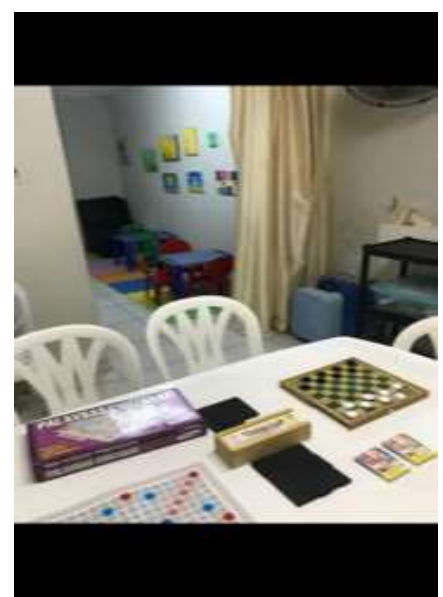

Fonte: Acervo das autoras (2019). 
Com o objetivo de caracterizar o nível de compreensão, utilizamos jogos e percebemos a capacidade de memória, raciocínio lógico e agilidade. O lúdico conduz para o diagnóstico. "O estágio é o lócus onde a identidade profissional do aluno é gerada" (BURIOLLA, 20oI, p.I3). Diante de tal afirmação, constatou-se que toda a experiência vivida no estágio foi de primordial importância para nós, pois relacionar o aprendizado recebido com a vivência trouxe autonomia profissional.

“A queixa não é apenas uma frase falada no primeiro contato, ela precisa ser escutada ao longo de diferentes sessões diagnósticas, sendo fundamental refletir sobre o seu significado" (WESS, 2004, p. 45). Observar palavras ditas pela mãe no decorrer das sessões é necessário, pois no primeiro contato muitas vezes os pais ainda não confiam e com o tempo eles repassam naturalmente.

\section{CONSIDERAÇÕES FINAIS}

Este estudo de caso buscou demonstrar que a aprendizagem da criança inicia no âmbito familiar e que a falta de estímulo logo cedo pode causar problemas. A escola sinaliza a falta ou excesso de atenção por parte dos alunos. A avaliação do professor e a interação da criança são importantes para analisar se existe defasagem cognitiva. A família e a escola caminham juntas, aprender é de responsabilidade da família também, o conhecimento prévio que o discente leva para a escola é importante.

"Nossa preocupação agora é captar as mensagens da criança através do corpo" (FERREIRA, 20or p. 46). A escola traz consigo a responsabilidade de acompanhar o desenvolvimento escolar, caso perceba algum sinal de dificuldade neste processo, a família é informada e orientada a procurar um psicopedagogo.

O trabalho do psicopedagogo deve ser em conjunto com a família e a escola, assim o diagnóstico é preciso e a criança aprende de maneira sadia. Atuar como espectador é um perigo, ela precisa participar e assim adquirir o conhecimento compatível com sua idade.

\section{REFERÊNCIAS BIBLIOGRÁFICAS}

BURIOLLA, Marta. Estágio Supervisionado. I틀 - São Paulo, 200 I.

FERREIRA, Márcia. Ação Psicopedagógica na sala de aula: uma questão de inclusão. $2^{-}$Ed - São Paulo, 200I. 
GOMES, Maria de Fátima Cardoso. Dificuldades de aprendizagem na alfabetização/ organizado por Maria de Fátima Cardoso Gomes, Maria das Graças de Castro Sena - $2^{\underline{a}}$ ed. 2-ㅡㄹ reimp. - Belo Horizonte: Autêntica, 2004.

SAMPAIO, Simaia. Dificuldades de Aprendizagem: a Psicopedagogia na relação sujeito, família e escola. $3^{\underline{a}}$. Ed. Rio de Jjaneiro: Wak editora, 2011.

VISCA, Jorge. Psicopedagogia: novas contribuições. Rio de Janeiro: Nova fronteira, I99I.

WESS, Maria Lúcia Lemme. Psicopedagogia clínica: uma visão diagnóstica dos problemas de aprendizagem escolar. Io ${ }^{-}$Ed. I ${ }^{-a}$ reimp. -Rio de Janeiro, 2004. 